ISSN: 2146-3042

DOI: $10.25095 /$ mufad.710228

\title{
Türkiye'deki Finansal Raporlama Çerçevelerine Göre Devlet Teşviklerinin Karşılaştırmalı Analizi: Turizm Sektörü Örneği*
}

\author{
Firat ALTINKAYNAK* \\ Özlem DOĞAN**
}

\begin{abstract}
ÖZET
Turizm sektöründe, gerek yatırım maliyetlerinin yüksek olması gerekse hizmet üretimindeki birtakım zorluklar, devlet teşviklerininönemini artırmaktadır.

Bu çalı̧̧manin amacl, devlet teşviklerinin Türkiye' deki finansal raporlama çerçevelerine göre benzer ve farkll yönlerini ortaya koyarak, kaylt farkllıkları doğrultusunda öneriler getirmektir. Bu bağlamda, turizm sektöründeki devlet teşvikleri, Türkiye'deki finansal raporlama sistemlerine göre tanımlanmış ve bu doğrultuda turizm sektörü için örnek uygulamalar yapılmıştır.

Çalışmanın sonucunda, finansal raporlama çerçeveleri açısından muhasebe kayıtlarındaki benzer ve farkl yönler tespit edilmiş ve tablo halinde ortaya konulmuştur. Bu konuda yapılan düzenleme farklllıkları, işletmeleri muhasebe politikalarında farklı uygulamalara yönlendirmektedir. Farklı uygulamalar sonucu ortaya çıkan finansal tabloların gerçeğe uygun ve karşılaştırılabilir olma özellikleri zedelenebilmektedir. Bu bağlamda çalışma sonucunda getirilen öneri, her sektör için verilen devlet teşviklerinin muhasebeleş̧tirilmesinde, ilgili sektöre özgü tek bir kayıt yaklaşımının uygulanmasıdır. Bu uygulama ile sektörel bazda, tüm finansal tablolar karşılaştırılabilir, analize yatkın ve tutarlı olacak ve böylelikle finansal tablolar işletme ilgilileri tarafindan açı ve net bir şekilde yorumlanabilecektir.

Anahtar Kelimeler: Devlet Teşvikleri, Finansal Raporlama Çerçeveleri, Turizm Sektörü.

JEL Sinıflandirması: M40,M41.
\end{abstract}

\section{Comparative Analysis Of Government Grants In Financial Reporting Frameworks In} Turkey: Example Of Tourism Sector

\section{ABSTRACT}

It increases the importance of government grants in tourism sector due to both the high investment costs and some difficulties in service production.

The purpose of this study is to reveal similar and different aspects between the records which was made in financial reporting systems and offering suggestions in accordance with these record differences. In this context, government grants which was used in tourism sector were described arrangements according to financial reporting systems in Turkey and it has been made sample applications for the tourism sector according to the financial reporting systems in the study.

The similar and different aspects in the accounting records have been determined and presented with a table in terms of financial reporting systems at the result of this study. Regulatory differences which was made in this regard direct the enterprises to different practices in accounting policies. The financial statements which was created as a result of the different applications may be damaged to characteristics of truthful and comparable. In this context the suggestion which was offered at the result of the study is the implementation of a single registration approach specific to the relevant sector in the accounting of government grants for each sector. All financial statements will be comparable, consistent and prone to analysis on the sectoral basis with this practices and hereby the financial statements will may be interpreted graphically and clearly by the business related persons.

Keywords: Government Grants, Financial Reporting Frameworks, Tourism Sector.

Jel Classification: $M 40, M 41$.

* Makale Gönderim Tarihi: 03.05.2019, Makale Kabul Tarihi: 07.08.2019, Makale Türü: Araştırma Makalesi

* Dr. Öğr. Üyesi, Sakarya Uygulamalı Bilimler Üniversitesi, Karasu Meslek Yüksekokulu, faltınkaynak@subu.edu.tr, Orcid ID: /0000-0003-0960-2254

** Dr. Öğr. Üyesi, İskenderun Teknik Üniversitesi, Barbaros Hayrettin Gemi İnşaatı ve Denizcilik Fakültesi, ozlem.dogan@iste.edu.tr, Orcid ID: 0000-0002-5752-9031 


\section{GíRiş}

Günümüz şartlarında özellikle gelişmekte olan ülkelerde ekonomik kalkınma ile istihdamı artırmak, bölgeler arasındaki sosyo-ekonomik gelişmişlik farklarını en aza indirmek, yeni yatırım alanlarının açılması, yabancı yatırımcılar için cazibe merkezlerinin oluşturulması gibi faaliyetlerde devlet destekleri oldukça önemlidir. $\mathrm{Bu}$ amaçlar doğrultusunda genellikle özel sektör kuruluşlarınadoğrudan parasal yardım, ucuz kredi kullandırma, vergi indirim ve istisnaları, ucuz hammadde temini gibi araçlarla birtakım destekler sağlanmaktadır. Bu uygulamalar Türkiye' de de yapılmakta olup "devlet teşvikleri” olarak literatüre girmiş bulunmaktadır.

Teşvik, "İktisat Terimleri” sözlüğünde "belirli bir iktisadi veya sosyal amaca ulaşabilmek için maddi destek ve hukuki kolaylıklar biçiminde verilen ödül” olarak tanımlanmıştır. Teşvik genel olarak, belirli ekonomik faaliyetlerin diğer faaliyetlere kıyasla daha fazla ve hızlı gelişmesini sağlamak amacıyla kamu tarafından çeşitli usullerle verilen maddi ve/veya gayri maddi her türlü destek, yardım ve özendirmelerdir. Teşvik sistemindeki esas amaç, kaynakların ülke ve bölge ekonomileri açısından kalkınma planları ve yıllık programlarda öngörülen hedefler ile uluslararası anlaşmalara uygun olarak en verimli ve faydalı kabul edilen alanlara yönlendirilmesi, tasarruflarla katma değeri yüksek yatırımların desteklenmesi, üretim ve istihdamın artırılması, yatırım eğiliminin devamlılığının sağlanması ve böylece sürdürülebilir kalkınmanın gerçekleştirilebilmesi, uluslararası rekabet gücünü artıracak ve yüksek teknoloji gerektiren büyük ölçekli yatırımların özendirilmesi, doğrudanyabancı yatırımların artırılması, bölgesel gelişmişlik farklılıklarının giderilmesi, çevre korumaya yönelik yatırımların artırılmasıdır (Serdengeçti, 2000:93, Gülmez ve Yalman, 2010:236, Savrul ve Doğru, 2013:4). Teşvikin temel özelliklerini şöyle siralamak mümkündür (Candan ve Yurdadoğdu;2017:157):

- Teşvikler devlet tarafından sağlanmaktadır.

- Genellikle özel sektör işletmelerine yönelik olmakla birlikte kamu kuruluşlarına da tahsis edilebilmektedir.

- Teşviklerde kamu kaynaklarının kullanımı sebebiyle, teşvikin devlete bir maliyeti söz konusudur. (Ucuz ya da karşılıksız kredilerle sağlanan kamu fonları, vergi indirimi ya da istisnası yoluyla vergi gelirlerinden feragat etme gibi.)

- $\quad$ Devlet için bir kaynak kaybı söz konusu olsa da tahsis edilen işletmeler için bir yarar söz konusudur.

- Teşvikler dolaylı veya dolaysız, açık veya gizli olarak verilebilirler.

- Teşvikler, bir yatırımın mahiyetini, bölgesini, sektörünü, büyüklüğünü ve zamanlamasını etkilemek amacına dönük verilebileceği gibi bölgeler arasındaki gelişmişlik düzeyindeki farklılıkların azaltılması amacıyla da verilebilir.

Türkiye'de teşvik politikaları; yatırımların artırılarak, yeni iş olanaklarının sağlanması ile istihdamın artırılmasına yönelik olarak Osmanlı İmparatorluğu'ndan bu yana uygulanagelmektedir. Türkiye Cumhuriyeti'nin kuruluşundan bugüne gelinceye kadar geçen 
sürede, Türkiye'de teşvik uygulamaları kalkınma planları ile yürütülmüştür. Ayrıca teşvikler, ülke çapında tüm sektörlere yönelik olabileceği gibi belirli bir sektöre yönelik olarak da uygulanmaktadır. Tüm sektörlere yönelik teşvikler; bölgesel gelişim programları araştırmageliştirme, kobiler, istihdam ve beceri kazandırma, dış ticaret, enerji kullanımında etkinlik, çevrenin korunması konularını kapsayan diğer yatay programlardan oluşmaktadır. Belirli sektörlere yönelik teşvikler ise daha çok tarım, demir-çelik, kömür, demiryolları, gemi imalatı, balıkçılık ve turizm alanında yoğunluklu olarak verilmektedir (Özçam, 2003:2).

Turizm sektörü hizmete yönelik bir sektör olması sebebiyle istihdam imkanı yaratması, ülkeye döviz girdisi sağlayarak ödemeler dengesine önemli katkı yapması, bölgeler ve sosyal gruplar arasındaki sosyo-ekonomik farklllkkların en aza indirilmesinde önemli bir rol oynaması, vergi gelirlerini artırması, ekonomik olarak bir değer arz etmeyen doğal ve tarihsel varlıkların bu anlamda değerlendirilmesini sağlaması, hem ülkeler hem de bölgeler arasında kültürel alışverişe imkan vererek barış duygusunun geliştirilmesi açısından önemli bir sektördür (Usta, 1992:45). Ancak turizm yatırımlarında geri dönüş süresinin uzun olması, bu yatırımların yüksek sermaye gerektirmesi, doğal afetler, siyasi ve sosyal olaylara karşı aşırı duyarlı olması nedeniyle yatırım riski de taşımaktadır. Dolayısıyla turizm sektörü, diğer sektörlerle iç içe geçen yapısı, alternatif turizm imkânlarının yaygınlaşması, yeni teknolojik imkânların sağlanması, turizm faaliyetlerinin hassas yapısı ve taşıdığı riskler dikkate alındığında sektöre yönelik teşvik uygulamalarının geliştirilmesini zorunlu hale getirmektedir (Şanlığlu ve Özcan, 2017:100). İşletmelerin faaliyet alanı her ne olursa olsun, çeşitli faaliyetler sonucu elde edilen devlet teşvikleri, işletmelerin mali yapılarını da etkilemektedir. $\mathrm{Bu}$ durumun, işletmenin finansal tablolarında yer alması ve işletmeyi ilgilendiren tüm işletme çevresiyle paylaşılması açık, anlaşı1ır, gerçeğe uygun ve dürüst muhasebe uygulamalarının bir gereğidir. Hâlihazırda Türkiye' deki birçok şirket açısından, üç ayrı finansal raporlama çerçevesinin olması, bu çalışmanın doğmasına ve turizm sektörüne verilen devlet teşviklerinin MSUGT(Muhasebe Sistemi Uygulama Genel Tebliği), TMS 20(Türkiye Muhasebe Standardı 20 Devlet Teşvikleri ve BOBİ FRS (Büyük ve Orta Boy İşletmeler İçin Finansal Raporlama Standartları) Bölüm 16 açısından değerlendirilmesinin gerekliliğini ortaya çıkarmıştır. Çalışmada öncelikli olarak turizm sektörüne yönelik teşvik uygulamalarına yer verilmiş ve turizm işletmelerinin söz konusu teşviklerden faydalanmaları durumunda bunu muhasebe kayıtlarına nasıl yansıtacakları örneklerle açıklanmaya çalışılmışıtır.

\section{TURİZM SEKTÖRÜNDE UYGULANAN DEVLET TEŞVIKLERİ}

Dünya genelinde yaşanan küresel hareketlilik turizmin doğasından gelen hareketliliği desteklemiş ve günümüzde turizm dünya ölçeğinde ülke ekonomileri için önemli bir sektör haline gelmiştir. Bununla birlikte turizm sektörünün ulaştırmadan gıdaya, iletişimden konaklamaya birçok sektörü de etkilemesi turizmin önemini daha da artırmıştır. Dolayısıyla turizm konusunda kendini geliştiren ülkeler hem rekabetçi güçlerini hem de turizm gelirlerini artırmışlardır (Bahar,2007:64).

Türkiye'de turizmin teşvik edilmesi amacıyla yapılan ilk yasal düzenleme 1950 yılında "5647 Sayılı Turizm Müesseseleri Teşvik Kanunu" ile çıkarılmıştır. Bu kanunda turizm işletmeleri tanımlanarak, teşviklerden faydalanabilecek işletmelerin özellikleri ile koşulları açıklanmış ve denetimine yönelik düzenlemelere de ayrıca yer verilmiştir. İkinci yasal düzenleme ise 1953 yılında 6086 sayılı "Turizm Endüstrisini Teşvik Kanunu” ile özel sektörün turizm yatırımlarına teşvik edilmesi amacıyla yapılmış ve teşvik kapsamında on 
yıllık bir vergi muafiyeti de sağlanmıştır. 1980 yılında, 8/1133 sayılı "Turizm Teşvik Çerçeve Kararı" çıkarılmıştır. Çıkarılan bu kararla sektör için yatırım yapılacak alanlar belirlenmiş, yeni finansman kaynak ve yöntemleri oluşturulmuş, yabancı sermayenin çekilmesi ve turizm yatırımlarının teşvikine yönelik düzenlemeler yapılmış ve tüm bunlarla beraber "Turizm Koordinasyon Kurulu" oluşturulmuştur. 1982 yılında çıkarılan 2634 sayılı Turizm Teşvik Kanunu, turizm sektörünün bugünkü duruma gelmesinde önemli rol oynamıştır (Toker, 2007:82).

\section{TURIZM SEKTÖRÜNE YÖNELIK DEVLET TEŞVIKLERININ MUHASEBELEŞTIRILMESI}

Çalışmanın bu kısmında öncelikli olarak devlet teşviklerinin muhasebe kayıtlarında yer almasına yönelik hükümler içeren MSUGT, TMS 20 ve BOBİ FRS hakkında bilgi verilmiş, ilgili düzenlemelerin devlet teşviklerini ilgilendiren hususları incelenmiștir. İlgili yasal düzenlemeler veaçıklamaların ardından, karşılaşıırmalı olarak, muhasebe kayıtlarına yer verilmiş̧ir.

\subsection{Devlet Teşviklerinin Msgut Kapsamında Muhasebeleştirilmesi Yönündeki Esaslar}

Bir devlet teşvikinin muhasebe kayıtlarına alınabilmesi ve finansal tablolara yansitılabilmesi için, finansal olmayan devlet teşvikleri ile beraber, işletmenin gerekli olan tüm koşulları yerine getirmesi ve makul bir güvencenin sunulması gerekmektedir. Buradaki makul güvence, teşvikin elde edileceğine dair tutarlı belirtilerin olduğunu ve elde edilebilme ihtimalinin yüksek olduğunu ifade etmektedir(Onay, 2016:37).

MSGUT, "Muhasebenin Temel Kavramları", "Muhasebe Politikalarının Açıklanması", "Mali Tabloların, Düzenlenmesi ve Sunulması İlkeleri, Tekdüzen Hesap Planı ile İşleyişi’” konularında ortak bir yapı oluşturabilmek amacıyla, Maliye Bakanlığı tarafindan, 213 sayılı Vergi Usul Kanunu'nun 75 ve mükerrer 257. maddesine dayanılarak yapılmış düzenlemelerden oluşmaktadır.

MSUGT'da yer alan devlet teşviklerinin nasıl muhasebeleştirileceği ve finansal tablolarda nasıl yer alacağı ile ilgili açıklamalar 1 sıra nolu tebliğde, "Muhasebe Usul ve Esasları" bölümünün "V- Tekdüzen Hesap Çerçevesi, Hesap Planı ve Hesap Planı Açıklamaları" kısmında açıklanmıştır. İşletmelerin kullandıkları devlet teşviklerinin bu tebliğ gereği, "602.Diğer Gelirler" hesabında izlenmesi gerektiği belirtilmiştir.

"602. Diğer Gelirler" hesabı, tebliğde şu şekilde açıklanmıştır: "İ̧sletmenin korunması, ihracatı teşvik ya da hükümet politikasina uyma zorunluluğu karşısinda oluşan işletmenin faaliyet hasılatındaki düşüklüğü veya faaliyet zararın gidermek için, sermaye katkssı niteliğinde olmayan, mali yardımlar (sübvansiyonlar), devletin bazı malları vergi, resim, harç ve benzeri yükümlülü̈klerden istisna etmesi yoluyla yaptı̆̆ yardımlar (vergi iadeleri) ve satı̧ tarihindeki vade farkları, ihracatla ilgili fiyat istikrar destekleme primi vb. hasılat kalemleri bu hesapta izlenir."(www.gib.gov.tr). 


\subsection{TMS 20 Standardına Genel Bir Bakış}

UMS 20' den direkt Türkçe' ye çevrilen TMS 20'ye (Türkiye Muhasebe Standardı 20) göre devlet teşviki, işletmenin faaliyet konuları ile ilgili belirli koşulların geçmişte veya gelecekte yerine getirilmesi karşılığında işletmeye kaynak transferi şeklindeki devlet yardımlarıdır. Bu teşvikler, bir değer atfedilmeyen devlet yardımlarını ve işletmenin normal ticari işlemlerinden ayırt edilemeyen devlet ile yaptığı işlemleri kapsamaz (TMS 20, madde $3)$.

TMS 20 standardı, devlet teşviklerinin ölçümü, muhasebeleştirilmesi ve raporlanması konusundaki düzenlemelerin yanı sıra devlet yardımları ile ilgili düzenlemeleri de kapsamaktadır. Ancak gelişmekte olan bölgelerde alt yapı sağlanması veya rakipler üzerine ticari kısıtlamalar getirilmesi gibi genel ticaret koşullarını etkilemek suretiyle sadece dolaylı olarak sağlanan faydalar yardım kapsamında değildir. Yardımın amacı, bir işletmeyi devlet yardımı sağlanmadan normal koşullar altında yapamayacağı bir takım işlere girebilmesini teşvik etmektir. Devlet yardımı şayet bir kaynak transferi olarak gerçekleşti ise muhasebeleştirilmesi için uygun bir yöntem bulunmalı ve raporlama döneminde finansal tablolarda belirtilmelidir(TMS 20, madde 3,4,5).

\subsubsection{TMS 20 Standardına Göre Teşvik Türleri}

Standarda göre devlet teşvikleri, teşvik konusu varlığın niteliğine göre olan parasal teşvikler ve parasal olmayan teşvikler ile teşvik türüne göre olan geçmişte gerçekleşmiş gider ve zararları karşılamak için sağlanan teşvikler, koşulsuz teşvikler ve koşullu teşvikler olarak gruplandırılabilmektedir(Gürbüz ve diğerleri 2011, s.297):

- $\quad$ Parasal Teşvikler:İşletmeye doğrudan nakit ya da nakit benzeri varlıkların transfer edilmesi veya devlete olan bazı yükümlülüklerin azaltılması şeklindedir.Örneğin, devletten alınan krediler ve piyasa faiz oranından düşük bir oranla alınan kredinin faydası devlet teşviki olarak kabul edilmektedir.

- $\quad$ Parasal Olmayan Teşvikler:İşletmenin kullanması amacıyla verilen arsa veya diğer kaynaklar gibi parasal olmayan teşviklerdir. Böyle durumlarda genel uygulama olarak, teşvik konusu parasal olmayan varlığın gerçeğe uygun değerinin tespit edilerek, varlığın belirlenen gerçeğe uygun değer ile finansal tablolarda raporlanması sağlanmaktadır(TMS 20, madde 23). Standarda göre, devlet teşviki gerçek değer üzerinden ya da alternatif yöntem olarak, nominal değer üzerinden kaydedilmektedir.

- Geçmişte Gerçekleşmiş Gider ve Zararların Karşılanması Amacıyla Yapılan Teşvikler: $\mathrm{Bu}$ teşviklerin amacı, işletmenin geçmişte katlanmış olduğu bir maliyetin karşılanmasıdır. Örneğin, deprem bölgesindeki işletmelerin zararlarını telafi etmek için SGK(Sosyal Güvenlik Kurumu) yükümlülüklerinin bir kısmının silinmesi bu tür bir teşviktir(Y1lmaz,2014:61).

- Koşulsuz Teşvikler: $\mathrm{Bu}$ teşviki hak etmek için işletmenin daha önceden belirlenen koşulları gerçekleştirmiş olması şartı bulunmamaktadır. Genel ihtiyaçları karşılamak amacıyla yapılan teşviklerdir. Ar-Ge yapan şirketleriteşvik amacıyla, bu 
işletmelere yapılan maddi yardımlar koşulsuz teşvik olarak nitelendirilebilir(Akdoğan, 2011:266).

- Koşullu Teşvikler:Bu teşvikler, faydalanmak isteyen işletmelerin, teşvik öncesinde belirli koşulları yerine getirmesi yükümlülüğü bulunan teşviklerdir. Bu teşvikler, varlı̆ga ve gelire dayalı olmak üzere iki gruba ayrılmaktadır.

\subsubsection{Devlet Teşviklerinin Tms 20 Kapsamında Muhasebeleştirilmesine İlişkin Esaslar}

Devlet teşviklerinin elde edilme şekli, teşvikin muhasebeleştirilme yöntemini etkilememektedir. "TMS20 Devlet Teşviklerinin Muhasebeleştirilmesi ve Devlet Yardımlarının Açıklanması"standardı kapsamında devlet teşviklerinin muhasebeleştirilmesinde dikkat edilmesi gereken farklı hususlar yer almaktadır. Bu hususlar aşağıda açıklanmıştı:

Amortismana tabi olmayan varlıklara ilişkin teşvikler, belirli yükümlülüklerin yerine getirilmesinde katlanılan maliyetlerin gerçekleştiği dönemler boyunca kar yada zararda muhasebeleştirilir (TMS 20, md 18).

$>\quad$ Bazı durumlarda teşvikler hem varlıklara hem de gelire ilişkin bir teşvik olabilir. Bu gibi durumlarda teşvikin bir bölümü varlıklara diğer bölümü de gelire ilişkin esasa göre ilgili dönemlere dağttılması daha uygun olacaktır(Ulusan,2008:422).

$>$ Devlet teșvikleri mali tablolara yansıtıldıktan sonra bunlara ilişkin durumlar "TMS 37 Karşılıklar, Koşullu Borçlar ve Koşullu Varlıklar" standardı uyarınca muhasebeleştirilir.

Devlet teşviklerinin muhasebeleştirilmesinde, "Gelir Yaklaşımı" ve "Özkaynak Yaklaşımı" olmak üzere iki farklıyöntem bulunmaktadır(TMS 20, madde 13).

Gelir yaklaşımının dayandığı gerekçeler şunlardır(TMS 20, madde 15):

- Devlet teşvikleri, hissedarlar dışındaki bir kaynaktan elde edilmiş olmaları nedeniyle, doğrudan öz kaynak olarak kaydedilmemeli, fakat uygun dönemlerde kar ya da zarar olarak muhasebeleştirilmelidir.

Devlet teşvikleri nadiren karşılıksızdır. İşletmeler koşullara uymakla ve önceden konulan yükümlülükleri yerine getirdiği takdirde teşvik almaya hak kazanır. Bu nedenle teşvikler, sözü edilen teşviklerle karşılanması amaçlanan maliyetlerin gider olarak muhasebeleştirildiği dönemler boyunca kar ya da zararda muhasebeleştirilmelidir. Ayrıca gelir vergisi ve diğer vergilerin bir tür harcama olduğu göz önüne alındığında, mali politikaların bir uzantısı olan devlet teşvikleri de kar veya zararla ilişkilendirilmelidir.

TMS 20 kapsamında devlet teşviklerinin muhasebeleştirilmesinde bir diğer yöntem olan "Özkaynak Yaklaşımı" nın dayandığı gerekçeler ise aşağıda belirtilmektedir:

Teşviklerde geri ödeme beklenmediğinden dolayı, devlet teşviklerigelir tablosu dışında muhasebeleştirilmelidir. 
- Devlet teşviklerinin ilgili şirkete bir maliyeti olmadığından dolayı, gelir ve giderle ilişkilendirilmemelidir. Zira teşvikler kazanılmış bir gelir değildir.

Belli bir dönem sonunda geri ödenecekteşvikler ise, bir muhasebe tahmininin değiştirilmesi olarak, "TMS 8 Muhasebe Politikaları, Muhasebe Tahminlerinde Değişiklikler ve Hatalar" standardı uyarınca muhasebeleştirilir.

\subsection{BOBİ-FRS Kapsamında Devlet Teşviklerinin Muhasebeleştirilmesi}

\subsubsection{BOBİ-FRS Bölüm 16 Kapsamında Devlet Teşvikleri}

Büyük ve Orta Boy İşletmeler İçin Finansal Raporlama Standardı (BOBİ FRS) 29 Temmuz 2017 tarih ve 30138 (Mükerrer) Sayılı Resmi Gazete'de "Büyük ve Orta Boy İşletmeler İçin Finansal Raporlama Standardı Hakkındaki 56 Sıra Numaralı Tebliğ" ekinde 01.01.2018 ve devamında başlayan hesap dönemlerinde uygulanmak üzere yayınlandığı tarih itibariyle yürürlüğe girmiştir. Bu tebliğin amacı, Türkiye Muhasebe Standartları (TMS) ile Türkiye Finansal Raporlama Standartlarını (TFRS) uygulama zorunluluğu bulunmayan Kamu Yararını İlgilendiren Kuruluşlar (KAYIK) ve bağımsız denetime tabi işletmeler için münferit veya konsolide finansal tabloların gerçeğe ve ihtiyaca uygun olarak karşılaştırılabilir bilgi sağlamasını temin etmektir. BOBİ FRS, 19/12/2012 tarihli 2012/4213 Say1l Bakanlar Kurulu Kararı ile yürürlüğe konulan "Bağımsız Denetime Tabi Olacak Şirketlerin Belirlenmesine Dair Karar" uyarınca bağımsız denetime tabi olup, 26/08/2014 tarihli ve 29100 Sayılı Resmi Gazete'de yayımlanan 26 sayılı Kurul Kararı kapsamında TFRS uygulamayan işletmeler tarafindan münferit ve konsolide finansal tablolarının hazırlanmasında uygulanması zorunlu tutulmuştur(Karacan ve Uygun, 2018:799, Doğan, 2017:771).

BOBİ-FRS 27 bölüm ve 9 ek kısım olmak üzere 239 sayfadan oluşmaktadır. Bu bölümler arasında devlet teşvikleri BÖLÜM 16 'da açıklanmıştır. BOBİ-FRS'de devlet teşviki, faaliyet konularıyla ilgili belirli şartların karşılanması durumunda kaynak transferi şeklinde işletmelerce yapılan devlet yardımlarıdır.Devlet tarafından genel ticaret koşullarını etkileyerek geniş bir işletmeler topluluğuna sağlanan dolaylı katkılar devlet teşviki olarak değerlendirilemez(BOBİ FRS Bölüm 16, 2. Madde). Devlet tarafindan sağlanan ve önceden belirlenen şartlar karşıllığında devletin feragat ettiği krediler ve piyasa faiz oranından düşük bir faiz oranıyla devletten alınan bir krediden sağlanan faydalar ise devlet teşviki olarak kabul edilmektedir(BOBİ FRS Böl. 16, madde 6).

BOBİ FRS uyarınca devlet teşviklerinin ölçülmesi ve kayda alınması ile ilgili hususlar şunlardır(BOBİ FRS Bölüm 16, madde 7,8): üzerinden ölçülür.

Devlet teşviki alınan ya da alınacak olan varlı̆ı̆ın gerçeğe uygun değeri

- Alınan devlet teşvikleri, gelir tablosuna yansitılmalıdır. $\mathrm{Bu}$ teşvikler elde edildikleri andan itibaren, gelir tablosuna yansitllincaya kadar finansal durum tablosu içerisinde "Ertelenmiş Gelirler" içerisinde gösterilir. 


\subsection{MSUGT/TMS/BOBİ-FRS Açısından Devlet Teşviklerinin Muhasebeleştirilmesinde Uygulama Farklııkları}

MSUGT, TMS ve BOBİ FRS bazı noktalarda birbirini tamamlamakla birlikte bazı konularda ise farklı uygulamalar içermektedir. Devlet teşviklerinin ölçüm, kayıt ve raporlanmasına yönelik MSUGT, TMS 20 ve BOBİ FRS düzenlemeleri arasındaki temel farklılıklar aşağıdaki gibidir:

Tablo 2. MSUGT/TMS/BOBİ FRS Arasındaki Temel Farkl1lıklar

\begin{tabular}{|c|c|c|c|}
\hline & MSUGT & TMS & BOBİ FRS \\
\hline ADI & & $\begin{array}{l}\text { TMS-20 Devlet Teşviklerinin } \\
\text { Muhasebeleştirilmesi ve Devlet } \\
\text { Yardımlarının Açıklanması }\end{array}$ & $\begin{array}{l}\text { Bölüm 16- } \\
\text { Devlet Teşvikleri }\end{array}$ \\
\hline $\begin{array}{l}\text { Yayınlanma } \\
\text { Tarihi }\end{array}$ & $\begin{array}{l}26.12 .1992 \text { tarihinde } \\
21447 \text { sayıli Resmi } \\
\text { Gazete }\end{array}$ & $\begin{array}{l}\text { 15.01.2005 Tarih ve } 25701 \text { Say1l } \\
\text { Resmi Gazete }\end{array}$ & $\begin{array}{l}\text { 29.07.2017 Tarih ve } \\
30138 \text { Sayılı Resmi } \\
\text { Gazete }\end{array}$ \\
\hline $\begin{array}{l}\text { Yürürlük } \\
\text { Tarihi }\end{array}$ & $\begin{array}{l}1994 \text { y1lı hesap } \\
\text { döneminden itibaren }\end{array}$ & $\begin{array}{l}2006 \text { y1l1 hesap döneminden } \\
\text { itibaren }\end{array}$ & $\begin{array}{l}2018 \text { tarihi hesap } \\
\text { dönemi ve sonraki } \\
\text { hesap dönemleri }\end{array}$ \\
\hline
\end{tabular}

Bunlara ek olarak diğer benzerlik ve farklılıkları şöyle sıralamak mümkündür:

- Devlet teşvikleri TMS içerinde 20 nolu standartta, BOBİ FRS'de ise Bölüm 16 'da yer almaktadır. TMS 20'de devlet teşvikleri ve yardımlar BOBİ FRS'ye göre daha ayrıntılı değerlendirilmiştir.

- $\quad$ TMS 20'de standartta geçen, devlet teşvikleri, varlıklara ilişkin teşvikler, gelire ilişkin teşvikler, feragat edilebilir krediler, gerçeğe uygun değer kavramları tanımlanmıştır. Ancak BOBİ FRS'de sadece devlet teşviklerinin tanımına yer verilmiş ve düzenlemenin kapsamı açıklanmıştır.

- Devlet teşviklerinin kayıtlara alınmasında hem TMS 20 hem de BOBİ FRS, varlı̆ğın gerçeğe uygun değerinin dikkate alınmasını öngörmüştür.

- $\quad$ BOBİ FRS' de devlet teşvikleri; parasal olan ve olmayan, geçmişte gerçekleşmiş giderlere ilişsin teşvikler olarak sınıflandırılmaktadır. TMS 20'de ise koşullu ve koşulsuz olan, geçmişte gerçekleşmiş zararları karşılamak için sağlanan, varllğa ve gelire ilişkin teşvikler olarak sınıflandırılmıştır.

- TMS 20'de devlet teşviklerinin muhasebeleştirilmesinde teşvikin finansal durum tablosunda yer alması gerektiğini benimseyen sermaye yaklaşımı ve gelir tablosunda yer alması gerektiğini benimseyen gelir yaklaşımı olmak üzere iki yöntem sunulmuştur. BOBİ FRS'de ise uygulama farklılıklarına yer verilmemiş olup, teşviklerin alındıkları anda, kar ya 
da zarara yansitılması gerektiği belirtilmektedir. Bu yaklaşım TMS 20'de yer alan gelir yaklaşımı ile aynı amaca hizmet etmektedir.

- MSUGT, devlet teşviklerinin “602. Diğer Gelirler” hesabının yer aldığı,"Brüt Satışlar" grubunda izlenmesini önermektedir. Buna karşın MSUGT, TMS 20 ile paralel olarak devlet teşvikini bir gelir kalemi olarak görmekte ve "649 Diğer Olağan Gelir ve Karlar" yada "679. Diğer Olağandışı Gelir ve Karlar" hesaplarında izlenebileceğini belirtmektedir. MSUGT ile TMS 20 'de belirtilen gelir yaklaşımı ve BOBİ FRS gereğince devlet teşvikleri, gelir tablosunda, TMS 20' deki sermaye yaklaşımına göre ise finansal durum tablosunda raporlanmalıdır.

\section{TURIZZM SEKTÖRÜNDE DEVLET TEŞVIKLERININ MSUGT/TMS/BOBİ FRS AÇISINDAN MUHASEBELEŞTIRIILMESINE YÖNELIKK UYGULAMA ÖRNEKLERI}

Turizm sektöründe teşvik araçları özellikle alt ve üst yapı arzının oluşturulmasında kullanılmaktadır. Ancak bunların yanı sıra sektörü teşvik amaçlı olarak; kamu arazilerinin tahsisi, ucuz turizm kredileri, vergi resim ve harçlardan muafiyet, enerji desteği, personel çalıștırma kolaylığı, alt yapı yatırımlarında destek ve öncelik gibi uygulamalar da yapılmaktadır(Aydoğuş vd.,2006:4). Teşvikten faydalanan işletmelerin mali tablolarının gerçek ve güvenilir bir yapıya sahip olması adına bu teşviklerin belirlenen usuller dahilinde mali tablolara alınması gerekmektedir.

Çalışmanın bu bölümünde turizm sektöründe kullanılan teşviklerin MSUGT/TMS/BOBİ FRS hükümlerine göre muhasebe kayıtlarının yapılmasına ilişkin örnek uygulamalara yer verilmiş ve uygulama farklılıkları ve benzer yönleri ortaya koyulmaya çalışılmıştır

Örnek 1: Yalı Turizm A.Ş. Mayıs 2018 tarihli elektrik faturasını12.000 TL+ KDV olarak nakden ödemiştir. İşletme enerji konusunda devlet teşviki için Hazine Müsteşarlığı’na başvurmuş ve 8.000 TL teşvik almıştır. Elektrik faturasının tahakkuk ve ödeme kaydında MSUGT/TMS 20/BOBİ FRS hükümlerine göre bir farklılık bulunmamaktadır.

Faturanın tahakkuk ve ödeme kaydı:

\begin{tabular}{|c|c|c|}
\hline 740 HİZMET ÜRET.MAL. & 12.000 & \\
\hline 191 İND. KDV & 2.160 & \\
\hline 381 GIDERR TAHAKKUKLARI & & 14.160 \\
\hline 381 GIDER TAHAKKUKLARI & 14.160 & \\
\hline $100 \mathrm{KASA}$ & & 6.160 \\
\hline
\end{tabular}


MSUGT'a göre elde edilen devlet teşviki için yapılan başvurunun kabul edilmesi kayd1:

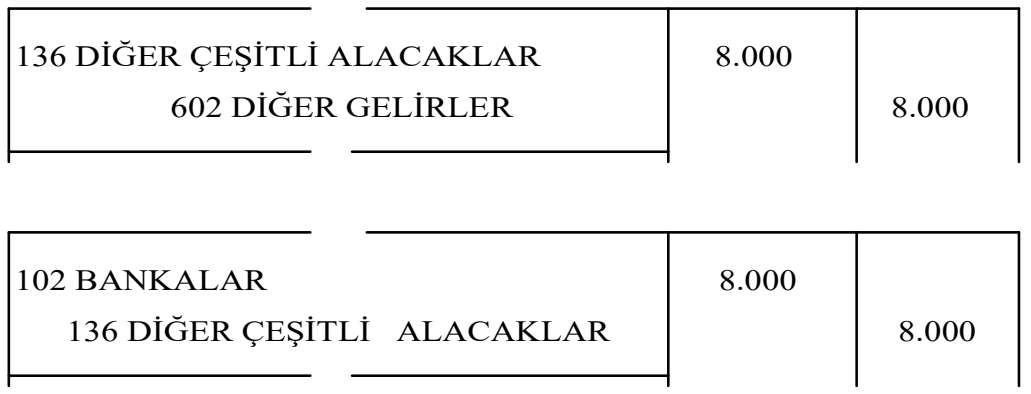

MSUGT'a göre devlet teşvikleri işletmeye ödendiği takdirde teşvik tutarı dönemin gelir tablosuna alınarak dönem gelirleri arasında gösterilmektedir.

Muhasebe standartlarının gereklerini karşılayan hesap planı taslağı, uzun yıllardır süregelen çalıştaylarda birçok akademisyenin, meslek mensubunun ve uzmanların öngörüsü ile hazırlanmış ve 2019 yılı başında, KGK(Kamu Gözetimi Kurumu) tarafından yayınlanmıştır. $\mathrm{Bu}$ doğrultuda, taslak hesap planında, TMS 20'ye göre elde edilen devlet teşvikinin kaydı yapılırken gelir yaklaşımı ve sermaye yaklaşımına göre 2 farklı kayıt yapılacaktır.

Sermaye yaklaşımına göre yapılacak kayıt:

$$
\begin{aligned}
& 136 \text { DİĞER ÇEŞİTLİ ALACAKLAR } \\
& 546 \text { YEDEKLERDE İZLENEN } \\
& \text { DEVLET TEŞVIKK GELIRLERİ }
\end{aligned}
$$

$$
\begin{array}{l|l}
8.000 & \\
& 8.000
\end{array}
$$

Teşvikle ilgili süreç tamamlandıktan sonra, yedeklerde tutulan teşvik geliri, geçmiş yıl karlarına aktarılmalıdır. Bu bağlamda kayıt:

$$
\begin{array}{|}
546 \text { YEDEKLERDE İZLENEN } \\
\text { DEVLET TEŞVİK GELİRLERİ } \\
570 \text { GEÇMIŞ YIL KARLARI }
\end{array}
$$

8.000

8.000 
Gelir yaklaşımına göre yapılacak kayıt ise:

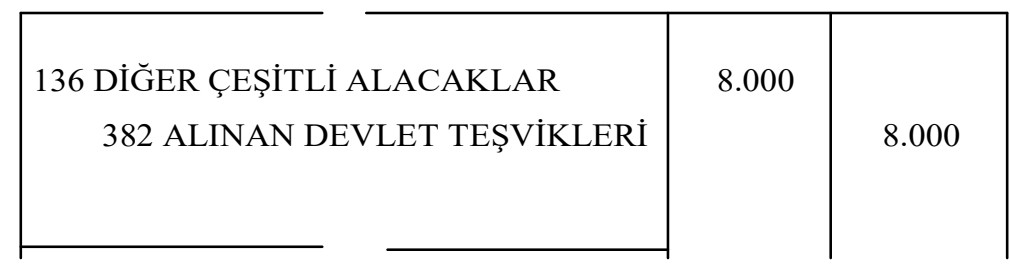

Devlet teşviki, ilgili dönemde gelire döndükçe, kar-zarar hesaplarına aktarılır. $\mathrm{Bu}$ bağlamda kayıt:

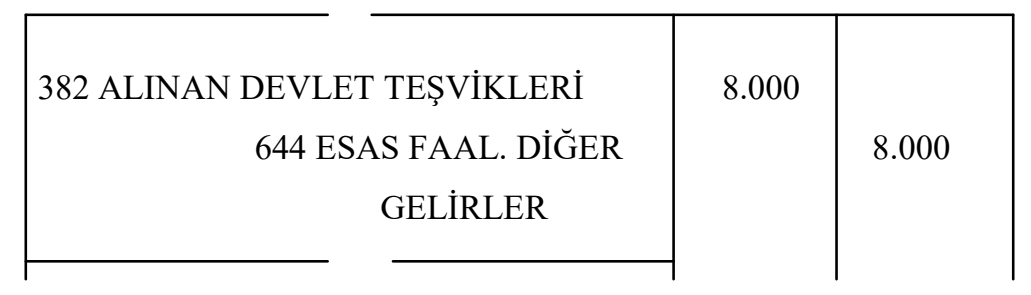

Yapılan kayıtlar dikkate alındığında standarda göre eğer sermaye yaklaşımına benimsendiği takdirde devlet teşvikinden elde edilen tutar finansal durum tablosunda raporlanacak, gelir yaklaşımı benimsenmesi durumunda ise gelir tablosunda raporlanacaktır.

BOBİ FRS'ye göre yapılacak kayıt ise:

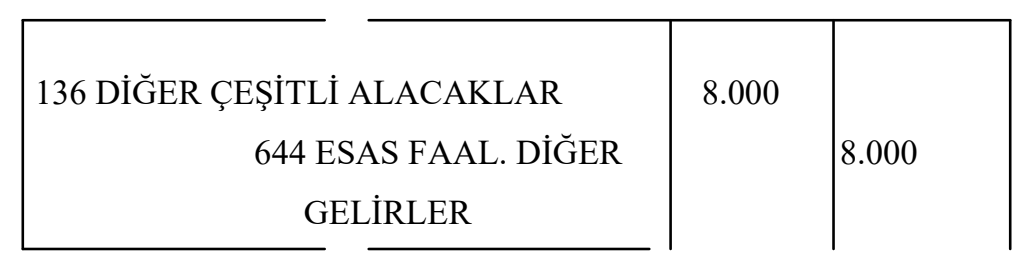

Yukarıdaki kayıtta da görüleceği üzere, BOBİ FRS, devlet teşviklerinin muhasebeleştirilmesinde, TMS 20'de belirtilen “Gelir Yaklaşımı” doğrultusunda kayıtların gerçekleştirilmesini önermektedir.

Örnek 2: Yalı Turizm A.Ş.'ye devlet teşviki kapsamında 20 yıllığına bedelsiz bir arazi tahsis edilmiştir. Arsanın değeri 280.000 TL olduğu tespit edilmiştir. 
MSUGT' a göre kayit;

\begin{tabular}{|c|c|c|}
\hline $\begin{array}{c}\text { 250 ARSA ve ARAZİLER } \\
602 \text { DİĞER GELİRLER }\end{array}$ & 280.000 & \\
& & 280.000 \\
\hline
\end{tabular}

TMS ve TFRS' ye uygun Taslak Hesap Planı uyarınca, TMS 20'ye göre elde edilen devlet teşvikinin sermaye yaklaşımına göre kaydı ise:

\begin{tabular}{|c|c|c|}
\hline 250 ARSA ve ARAZİLER & 280.000 & \\
546 YEDEKLERDE İLENEN & & \\
DEVLET TEŞVİK GELIRLERİ & & 280.000
\end{tabular}

TMS 20 gelir yaklaşımına göre kayıt;

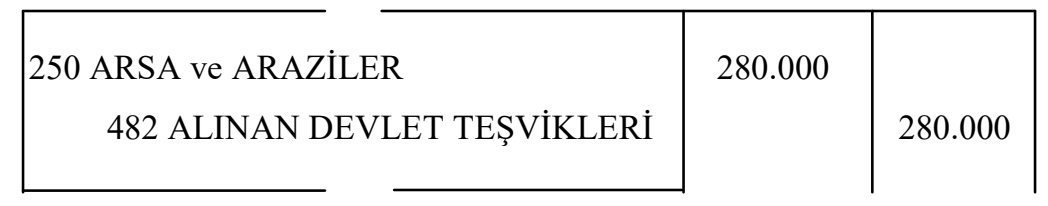

Tahsis edilen arazinin ilgili döneme isabet eden k1smı 280.000/20 y1l $=14.000 \mathrm{TL}$, ilgili dönemin devlet teşviki hesabına alınır.

\begin{tabular}{|c|c|c|}
\hline $\begin{array}{c}\text { 482 ALINAN DEVLET TEŞVIKLERİ } \\
\text { 382 ALINAN DEVLET TEŞVIKLERİ }\end{array}$ & 280.000 & \\
& & 280.000 \\
\hline
\end{tabular}


Teşvik o dönem içinde gelire dönüşünce, dönemin kar zarar hesaplarına yansıtılır.

\begin{tabular}{|c|c|c|}
\hline $\begin{array}{c}\text { 382 ALINAN DEVLET TEŞVIKLLEİ } \\
\text { 644 ESAS FAAL. DİĞER } \\
\text { GELİRLER }\end{array}$ & 280.000 & \\
\hline
\end{tabular}

BOBİ FRS' ye göre yapılacak kayıt ise yukarıda gösterilen, TMS 20' nin gelir yaklaşımı ile aynı yapıda olduğundan, mükerrer kayıttan kaçınılmaktadır.

Örnek 3:Yalı Turizm A.Ş., yurtdışında katılacağı bir turizm fuarı için 2010/9 sayılı "Yurtdışı Turizm Fuarlarına Katılımın ve Turizm Tanıtma ve Pazarlama Faaliyetlerinin Desteklenmesine İlişkin Tebliğ hükümlerine göre tanıtım teşviki almak üzere başvuru yapmıştır. İşletme fuara katılım için 5.200 Dolar harcama yapmıştır ve teşvik kapsamında $\% 50$ 'sini geri alabilecektir. (Dolar kuru, 1Dolar $=4 \mathrm{TL}$ )

Fuara katılım kayd1,

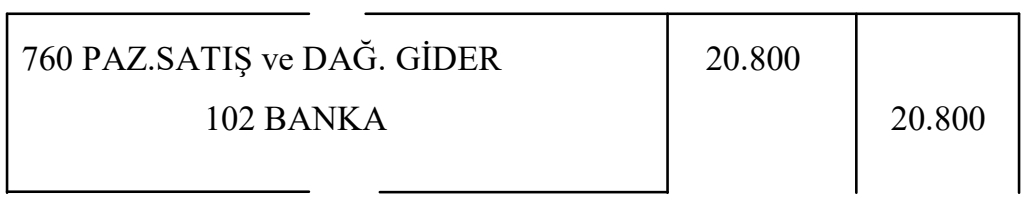

Teşvik için onay çıkmış ve işletmeye fuara katılım için yapılan harcamanın yarısı ödenecektir. Kur farkı göz ardı edilmiştir.

MSUGT'a göre kayıt,

\begin{tabular}{|c|c|c|}
\hline $\begin{array}{c}\text { 136 DİĞER ÇEŞ.ALACAKLAR } \\
602 \text { DİĞER GELİRLER }\end{array}$ & 20.800 & \\
\hline
\end{tabular}


TMS 20 kapsamında sermaye yaklaşımına göre yapılacak kayıt,

\begin{tabular}{|c|c|c|}
\hline 136 DİĞER ÇEŞ. ALACAKLAR & 20.800 & \\
546 YEDEKLERDE İZLENEN & & 20.800 \\
DEVLET TEŞVIK GELIRLERI & & \\
\hline
\end{tabular}

TMS 20 gelir yaklaşımına göre kayıt;

\begin{tabular}{|r|c|c|}
\hline $\begin{array}{l}\text { 136 DİĞER ÇEŞ. ALACAKLAR } \\
\text { 644 ESAS FAAL. Dİ̆ĞER } \\
\text { GELİRLER }\end{array}$ & 20.800 & \\
\hline
\end{tabular}

BOBİ FRS' ye göre yapılacak kayıt,

\begin{tabular}{|c|c|c|}
\hline 136 DİĞER ÇEŞ. ALACAKLAR & 20.800 & \\
$\begin{array}{c}\text { 644 ESAS FAAL. DİĞER } \\
\text { GELİRLER }\end{array}$ & & 20.800 \\
\hline
\end{tabular}

Teşvik tutarı işletmenin banka hesabına yatırıldığında yapılacak kayıt ise,

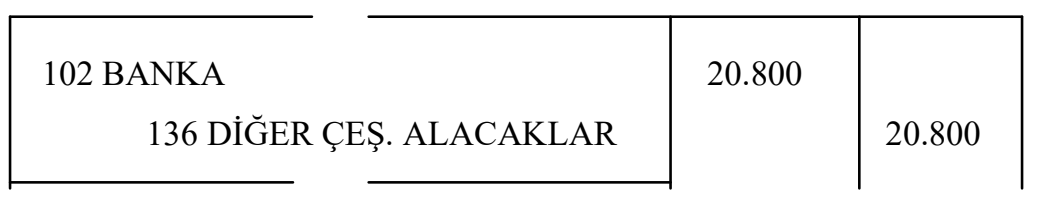

\section{SONUÇ VE ÖNERÍLER}

Turizm sektörü, Türkiye'nin sahip olduğu turizm potansiyeli açısından değerlendirildiğinde, devlet tarafindan desteklenmesi gerekli olan sektörlerin başında gelmektedir. Turizm sektöründeki kuruluş-örgütlenme ve işletme giderleri, diğer sektörlerle karşılaştırıldığında, hizmet üretimi nedeniyle, çok daha yüksek tutarlara ulaşmakta ve turizm işletmeleri yüksek maliyetlerle faaliyetlerini sürdürmektedirler. Dolayısıyla sektörün yüksek sermaye yatırımı gerektirmesi bu işletmeler için alınacak desteklerin de önemini artırmaktadir. 
Turizm işletmeleri için bedelsiz arazi tahsisinden enerji desteğine, tanıtım desteklerinden düşük faiz kolaylığına kadar,değişik zamanlarda, birçok farklı devlet teşviki imkanı bulunmaktadır. İşletmeler aldıkları devlet teşviklerini muhasebe kayıtlarına yansıtarak, işletme ile ilgili bilgi bekleyen taraflara güvenilir ve gerçeğe uygun bir raporlama sağlamalıdır. Bu noktadan hareketle, devlet teşviklerinin muhasebe kayıtlarına alınması ile ilgili olarak, MSUGT, TMS 20 ve BOBİ FRS' de hükümler yer almaktadır.

MSUGT'a göre, işletmelerin kullandıkları devlet teşvikleri“602 Diğer Gelirler” hesabında izlenmektedir. Bu hesap, işletmelerin esas ticari faaliyetlerden elde edilen gelirlerin bulunduğu "Brüt Satış Karı" hesap grubunda yer almaktadır. Ancak devlet teşviki işletmelerin ticari faaliyetleri nedeniyle elde ettiği bir gelir olmaması sebebiyle yapılan kayıt gerçeğe uygun bilgi içermemektedir. Ayrıca bu kayda göre hazırlanacak gelir tablosunda işletmenin "Brüt Satış Karı" yüksek çıkacaktır ve bu durum işletme yöneticilerinin ve işletmeyle ilgilenen diğer grupların (yatırımcı, finans kuruluşları, devlet gibi) yanlış kararlar almalarına sebep olabilecektir. Bununla birlikte Kurumlar Vergisi Kanunu' na göre bazı devlet yardımları, "Mali Kar" hesaplanmasında, kurum kazancından indirilebilirken, birçok devlet teşviki kurum kazancından indirilememektedir. Dolayısıyla birçok durumda, "Brüt Satış Karı" nın yüksek olması işletmenin vergilendirilebilir karını artırmakta ve işletme bir nevi elde ettiği devlet teşviki üzerinden vergi ödemektedir. Bu durum,işletmenin devletten aldığı teşvikin belli bir kısmını da devlete geri ödemesini gerektirmektedir.

Devlet teşviklerinin muhasebeleştirilmesindeki bir diğer uygulama "TMS 20 Devlet Teşviklerinin Muhasebeleştirilmesi ve Devlet Yardımlarının Açıklanması" standardıdır. Bu standarda göre teşviklerin kayda alınmasında gelir yaklaşımı ve sermaye yaklaşımı olmak üzere iki farklı yol gösterilmiştir. Gelir yaklaşımı devlet teşvikini bir gelir olarak görmesi nedeniyle MSUGT ile benzer özellikler taşımaktadır. Ancak MSUGT'dan farklı hesaplar kullanılmaktadır. KGK tarafından taslak halde yayınlanan tek düzen hesap planında devlet teşvikleri için özel hesaplar tanımlanmıştır. MSUGT ile benzer olarak bu yaklaşımda devlet teşviki gelir tablosunda yer almakta olup işletme gelirlerini yüksek görünmesine sebep olmaktadır. Sermaye yaklaşımında ise, devlet teşviklerinin bir gelir olmadığından hareketle ilgili tutarın bilanço hesaplarında yer alması gerektiği önerilmektedir. Bu yaklaşımda devlet teşvikine ait olan tutar, “546Yedeklerde İzlenen Devlet Teşvik Gelirleri” hesabında izlenmekte olup,teşvik sürecinin bitiminde, teşvik tutarı, "Geçmiş Yıl Karları" hesabına taşınmaktadır. $\mathrm{Bu}$ durum, işletmenin gelirlerini etkilememekte, öz sermayesini artırmaktadır. Gelir yaklaşımı ve sermaye yaklaşımı devlet teşvikine farklı açılardan yaklaşmakta, dolayısıyla işletmeleri farklı uygulamalara yönlendirmektedir. Her iki yaklaşımın da uygulanması konusunda işletmeler serbest bırakılmıştır. Ancak bu durum işletmelerin finansal tablolarının gerçeğe uygun, açık, anlaşılır ve karşılaştırılabilir bilgi sağlama işlevini zaman zaman zora sokabilmektedir. Zira, benzer özellikteki iki işletmeden gelir yaklaşımını benimseyen bir işletmenin karı, sermaye yaklaşımını benimseyen işletmeye göre daha yüksek çıkacak, dolayısıyla hem yatırımcılar hem de kreditörler verecekleri kararlarda yanılabileceklerdir. BOBİ FRS'ye göre ise devlet teşviklerinin kayıtlara alınmasında MSUGT ve TMS 20'de yer alan gelir yaklaşımına benzer bir uygulama benimsenmiştir. BOBİ FRS Bölüm 16 da, devlet teşvikleri, gelir hesaplarında izlenmekte ve gelir tablosunda raporlanmaktadır. Bunun doğal bir sonucu olarak da işletmenin gelirleri yükselmektedir.

Devlet teşviklerinin uygulanması ve kullanımı yasal olarak, Türkiye'de faaliyet gösteren en küçük çaplı işletmeden en büyük şirkete varana kadar, tüm işletmeler için öz 
olarak aynıdır. Ancak bu işletmelerin tabi olduğu muhasebe uygulamaları, aynı teşvikin farklı yöntemlerle ve hesaplarla kayıt altına alınmasına sebep olmaktadır. Bu durum farklı finansal tabloların ortaya çıkmasına neden olmaktadır. Bu nedenle özellikle Türkiye' ye özgü finansal raporlama çerçeveleri olan MSGUT ve BOBİ FRS kapsamında yapılan düzenlemelerde bir uygulama birliğine varılması, hem işletme yöneticileri hem yatırımcılar hem de finans kuruluşlarının doğru kararlar almalarının önünü açacaktır.

\section{KAYNAKLAR}

Akdeve, E.- Karagöl, E. T. (2013), "Geçmişten Günümüze Türkiye'de Teşvikler Ve Ülke Uygulamaları”, Dumlupınar Üniversitesi Sosyal Bilimler Dergisi, Sayı 37, ss.329-350

Akdoğan, M.U. (2011), "Türkiye Coğrafyasında Uygulanan Devlet Teşvikleri Ve Devlet Yardımlarının, Uluslararası Muhasebe Standartları Çerçevesinde Analizi", Muhasebe ve Bilim Dünyası Dergisi, Sayı:4, ss. 260-281

Aydoğuş, İ. - Soybal1, H. - Baytok, H. (2006, "Yunanistan İle Türkiye'de Uygulanan Turizm Yatırım Teşviklerinin Karşılaştırılması", Afyon Kocatepe Üniversitesi İ̈BF Dergisi, Cilt: VIII, Sayı:1, ss.1-22

Bahar, O. (2007), "Küreselleşme Sürecinde Türkiye'de Turizm Sektörüne Sağlanan Teşvikler”, Dokuz Eylül Üniversitesi Sosyal Bilimler Enstitüsü Dergisi, Cilt 9, Sayı:1, ss. $61-78$

Candan, G.T. - Yurdadoğ, V. (2017), “Türkiye'de Maliye Politikası Aracı Olarak Teşvik Politikaları”, Pamukkale Üniversitesi Sosyal Bilimler Enstitüsü Dergisi, Sayı 27, ss. $154-177$

Doğan, A. (2017), "Büyük ve Orta Boy İşletmeler için Finansal Raporlama Standardı ile TMS/TFRS Karşılaştırması", İşletme Araştırmaları Dergisi, Cilt:9, Sayı:4, ss. 770-786

Duran, M. (2003), Teşvik Politikaları ve Doğrudan Sermaye Yaklaşımları, T.C. Başbakanlık Hazine Müsteşarlığı, Ekonomik Araştırmalar Genel Müdürlüğü, Ankara.

Gülmez, M. -Yalman, N. İ. (2010), "Yatırım Teşviklerinin Bölgesel Kalkınmaya Etkileri: Sivas İli Örneği”, Atatürk Üniversitesi İktisadi ve İdari Bilimler Dergisi, Cilt: 24, Say1: 2, ss. $235-257$

Gürbüz G. - Ataman, B. - Çakıcı, C. (2011), Türkiye Finansal Raporlama Standartları Uygulamaları, Türkmen Kitabevi, İstanbul.

Karacan, S. - Uygun, R. (2018), "Büyük ve Orta Boy İşletmeler İçin Finansal Raporlama Standardı (BOBİ FRS) İle Türkiye Muhasebe / Finansal Raporlama Standartlarının (TMS/TFRS) Karşılaştırılması", Uluslararası Sosyal Araştırmalar Dergisi, Cilt:11, Say1:56, Nisan, ss.799-813

Karataş, G. - Tetik, N. (2018), "Turizm İşletmelerine Sağlanan Devlet Teşviklerinin Muhasebeleştirilmesinin TMS-20 Standardı ve Tekdüzen Muhasebe Sistemi 
Açısından Karşılaştırılması”, Muhasebe ve Vergi Uygulamaları Dergisi, 11 (1), ss. 126

Mckenzie, B. -Coetsee, D. - Njikizana, T. - Chamboko, R. - Colyvas, B. - Hanekom, B. (2012), Wiley IFRS 2013: Interpretationand Application of International Financial ReportingStandards, John Wiley\&Sons.

Onay, A. (2016), Muhasebe Standartları Kapsamında Devlet Teşviklerinin Muhasebeleştirilmesi, Aksaray Üniversitesi İktisadi ve İdari Bilimler Fakültesi Dergisi, 8 (3), ss.31-45

Özbirecikli, M. - Şen, İ.K. - Tüm, K. (2017), Uygulamaya Dönük Örnekli Açıklamalarla BOBİ FRS, Detay Yayıncılık, Ankara.

Özçam, M. (2003), Ekonomide Teşvikler ve Türkiye'de Son Durum, Sermaye Piyasası Kurulu Araştırma Raporu.

Sakarya, Ş. - Yazgan, K.F. - Yıldırım, H.H. (2018), "Büyük ve Orta Boy İşletmeler İçin Finansal Raporlama Standardı (BOBİ FRS)'nin Muhasebe Meslek Mensupları Tarafından Bilinirliğinin ve Farkındalığının Tespiti: Balıkesir İli Örneği”, Muhasebe ve Vergi Uygulamaları Dergisi, Nisan Özel Say1, ss. 699-724

Savrul, K. B. - Doğru, B. (2013), “TR 22 Düzey 2 Bölgesinin 2012 Yılı Teşvik Sistemi Çerçevesinde Değerlendirilmesi”, Çankırı Karatekin Üniversitesi İktisadi ve İdari Bilimler Fakültesi Dergisi, Cilt: 3, Say1: 1, ss. 1-20

Serdengeçti, T. (2000), Teşviklerin Genel Bir Değerlendirmesi, Ekonomik Gelişme, Teşvikler ve Sivas, (Ed: Erdinç Telatar), Türkiye Ekonomi Kurumu, Ankara

Şanlıoğlu Ö. - Özcan E.Ö. (2017), Türkiye'de Uygulanan Turizm Teşvik Politikaları ve Sonuçları Üzerine Bir Değerlendirme, Kırıkkale Üniversitesi Sosyal Bilimler Dergisi, cilt.7, ss.97-118

Şen, İ.K. - Özbirecikli, M. (2018), “BOBİ FRS'nin Muhasebe Uygulamalarına Getirdiği Değişiklikler: BOBİ FRS, TMS/TFRS ve Mevcut Muhasebe Sistemi Çerçevesinde Bir İnceleme", Muhasebe ve Vergi Uygulamaları Dergisi, Özel Sayı, ss.462-484

Toker, B. (2007), “Türkiye'de Turizm Sektörü Teşviklerinin Değerlendirilmesi”, Yönetim ve Ekonomi Dergisi, Cilt:14, Say1:2, ss.81-92

Tunçez, A. - Ateş, A. (2016), "Devlet Teşviklerinin Muhasebeleştirilmesi ve Devlet Yardımlarının Açıklanması Standardı (TMS 20) Kapsamında Turizm Sektöründe Muhasebe İşlemleri", Selçuk Üniversitesi Sosyal Bilimler Meslek Yüksekokulu Dergisi Cilt:19, 41.Y11 Özel Sayısı, ss.87-96

Usta, Ö. (1992), Turizm, Altın Kitaplar, İstanbul 
Yılmaz, E. (2014), "Türkiye Muhasebe Standartları Kapsamında Tarımsal Devlet Teşviklerinin Muhasebeleştirilmesi”, Muhasebe ve Bilim Dünyası Dergisi, Sayı:62, ss. $57-71$

Zeytinlioğlu, E. - Gönen, S. (2015), “Devlet Teşvik ve Yardımlarının TMS 20 Kapsamında Muhasebeleştirilmesine Yönelik Değerlendirmeler”, Dumlupınar Üniversitesi Sosyal Bilimler Dergisi, Sayı:45, ss.175-189

\section{İnternet Kaynakları}

http://www.kgk.gov.tr/Portalv2Uploads/files/Duyurular/v2/Diger/20172\%20bas\%C4\%B1n\% 20duyurusu.pdf (15.03.2019). 